\title{
Innovation in Mexican Micro and Small Businesses: Individual Skills and Knowledge
}

\author{
By Mario Alberto García-Meza* \\ Omar Neme-Castillo ${ }^{\dagger}$ \\ Ana Lilia Valderrama-Santibáñez
}

A way to increase the value added to micro and small businesses (MSB) is through innovation, which starts from an intellectual capital where skills, attitudes, motivations and knowledge are the key. Innovation is seen as a process that results from the formation of skills of labor, and education or training and experience that leads to individual innovation. Thus, externalities of such skills translate into successful innovation processes (generation, development or modification of products and processes). Also, in transit through the spiral of innovation, which involves one step of creativity and one of entrepreneurship, three interrelated types of human skills come into play: basic, secondary and innovative. Therefore, the aim of the paper is to describe the importance of the individuals' skills and knowledge to the innovation process in Mexican MSB.

Keywords: Innovation, Knowledge, Micro and small businesses (MSB), Skills, Spiral of innovation.

\section{Introduction}

Micro and Small Businesses (MSB) present advantages and disadvantages in the face of the changing environment of globalization that is reflected in their local markets. Despite their flexible structure, the lack of clear objectives, low availability of economic resources and scarce competitiveness makes them vulnerable to a globalized market.

Morales (2011) indicates that just one in ten new businesses achieve market consolidation a decade after starting operations. He identifies the lack of knowledge about the market, the product or service and the used inputs of clients, suppliers and competitors, among others, as closing causes.

A way to reduce the mortality rate and increase the value added by the MSB is innovation, therefore, a continuous effort of innovation is key for these kinds of businesses to grow and evolve. In general, innovation is seen as a process derived from the formation of skills, and it is believed that education, training and experience lead the individual to innovation. In consequence, skills, knowledge, attitudes and motivation play a central role in the innovation process (OECD 2011).

Innovation is a complex process of creation of novelties where different agents associate: firms, public and private organizations, educational institutions,

\footnotetext{
* PhD Student, National Polytechnic Institute, México.

${ }^{\dagger}$ National Polytechnic Institute, México.

ॠNational Polytechnic Institute, México.
} 
and others. For the MSB, individuals are a key component for any process of innovation. According to Freeman and Soete (1997) innovation is a process of adjustment that starts in the minds of creative people and materializes in new products, processes or services. Thus, innovation requires individuals to fulfill successfully this process. Businesses need innovative people with skills that can be grouped into creative, emotional, organizational and enforcement capacities. That is, people capable of creating solutions, generating new goods, designs, processes, services, methods or organizations, or increasing the value of the ones that already exist.

This work describes the importance of the skills and knowledge of the individual for the innovation process in the MSB. In the next section, the systemic approach of innovation for these kinds of businesses is proposed. Subsequently, the paper makes a brief description of some models of planned change on which innovation is based and presents the role of human skills for innovation. Finally, some conclusions are presented.

\section{Systemic Approach of Innovation in MSB}

To analyze and improve reality, micro and small businesses must follow a systemic approach. The General Systems Theory (GST) allows us to holistically describe phenomena, comprehend their relation with the environment, make predictions and create favorable situations for business growth. In this sense, GST is the cornerstone to understanding and promoting change in any system.

It is fundamental to define a system to conceptualize MSB, as such. A system is a unity that is composed of interdependent parts. It is dynamic, different and superior to the sum of its parts or constituents; whatever happens to one affects all the others. A system is contained, in turn, in other higher order systems (Velásquez 2007).

There are closed and open systems. The former behave in fixed ways without variations. These are systems where no outside element gets in and no inside element gets out. Closed systems are in some way self-sufficient. On the other hand, open systems communicate with their environment from which they receive a series of inputs (raw matter, energy, information) and in turn they supply a series of outputs. All social systems are open systems. In fact this openness is the cause that stimulates innovation in the firm. A business is an organizational system, open and alive, keeps a dynamic interaction with its environment, influences the environment and receives influence from it. In this sense, they have unlimited life as long as the system adapts to change (Velásquez 2007).

Quoting Velásquez (2007), the organization is an organic system immerse in a hostile medium with which energy, matter, information and money is interchanged, i.e., the organization is a socio-technical open system. Open systems have the following characteristics (Centro Ericksoniano 2014):

- Non-additive. The system is larger than the sum of its parts;

- Entirety. It is holistic, if a part changes, the whole system changes. It is a non-separable and coherent whole; 
- Linearity and Circularity of the information. When there is linearity the information flows in one way only. With circularity, information makes a round trip;

- Feedback. Positive, when a reaction, that reinforces the ongoing process, corresponds to an action. Negative when the reaction of one of the parts drags back the other;

- Equifinality. The same result can be achieved in various ways.

- Organization. There are hierarchies, the division of roles and specialization in the system.

- Bounds. The system is bounded and it can be told apart from its environment, with the entry and departure of the energy and information regulated. Bounds can be closed, permeable or inexistent; they can be modified so that the system adapts to an internal or environmental change;

- Hierarchy of complexity. Every system is part of one or many larger systems and its parts are systems that have their own parts;

- Homeostasis. It is the tendency of the system to recover equilibrium and stay in it.

- Entropy. It is the tendency of systems not to differentiate between their parts, which might lead them to disappear in the face of the loss of structure hierarchy and functions;

- Negentropy. Inverse process of entropy. Appears only in live systems, where there exists pressure or information to preserve order within the system. Its complexity increases through specialization, hierarchies and the creation of new structures.

Equifinality represents the options to change: it is always possible to find other ways to innovate. Organization and limits give structure to the system. The hierarchy of complexity allows seeing the business as a little part in between larger systems that can also be modified. Therefore, innovation processes implemented by the businesses that appear to be risky and uncertain, ultimately lead to equilibrium (Centro Ericksoniano 2014). Understanding change and the diverse ways to face or plan, it provides MSB with elements for innovation. GST is the starting point for processes of change in systems with human interaction where an invisible field of information exists. According to Bateson (1990), organizations are sentient entities, with faculties to generate and absorb information, for feedback and self-regulation.

Learning is, thus, essential for systemic thinking in the firms. As Senge (2004) explains, the implications of learning from a systemic perspective are more profound than the simple filtration or absorption of information; it implies facing the challenge to re-create the firm. Through learning, the MSB collaborators train and develop skills to do something they did not even consider was possible before. Through learning, firms amplify their capacity to create, to innovate. To Senge (2004), in a firm there exists adaptive learning, necessary to face unexpected crisis situations. But, in intelligent organization, adaptive learning and generative learning are combined. The latter augments creative capacity and allows foreseeing and planning the learning path. 
Three phases can be identified: $i$ ) Current state of things, ii) Transition phase and iii) New state. Change is necessary when the current results are no longer satisfactory. As Bateson (1990) says, the only thing we can be sure about is that the current situation will change, bringing new knowledge, structure and learning to the system. Jones (2013) argues that an organizational change is the process where organizations move from their current state to a desired future. It is a planned change that implies generated learning. Its goal is to find new or better ways to use resources, enlarge the organization capacity, create value and improve profitability.

To achieve change, modifications must be implemented to the system. Leaders within -be it owners or any other agent sincerely interested in changeshould start these modifications by individual learning. Then, they can use teamwork to promote change. These changes are expected to eventually leak to clients and suppliers, in order to adapt to the new, more efficient ways of the firm. Thus, the individual within the firm is the main agent of change.

There exist forces that promote change and forces that resist it. Within the first, there is competitiveness and the wish to achieve an advantage. Also, the demographic and social forces are important because they help create whole new segments. Forces that resist the changes are detected mainly in family-owned businesses where the limits and hierarchies get mixed with family bonds and household situations (Jones 2013).

The culture or original conception of the founder also creates a resistance to change when whoever makes decisions is not able to make serious alterations, to stay in a safe zone; this is associated with the idea of intergenerational succession (Gómez 2006). In some cases, some functional resistance can be found when there is a conflict of power between collaborators or bad communication. In small firms, at a group level, we can also find resistance caused by rigid norms (Robbins 1999).

Considering change forces at an individual level, the main force that stimulates change is the desire for self improvement (Adecco 2013), getting out of the daily routine (Ventura et al. 2006), the ability to visualize goals and the benefits of achieving them; while the forces of change-resistance are, a low tolerance to frustration ${ }^{1}$, fear of uncertainty ${ }^{2}$, risk aversion, ingrained habits (Lizatti 2008), etc.

Another important element is beliefs that can promote or resist change depending on the experience of the collaborators in the firm (Robbins 1999). To Cañeque (2008) it is just a matter of how someone feels and thinks in the face of change, and a matter of walking toward the proposed goals.

\footnotetext{
${ }^{1}$ This is associated with the idea of a work pseudo-satisfaction, in which the individual feels frustration but perceives the problems as unsolvable, keeping his level of aspirations and compromise.

${ }^{2}$ The comfort zone where people and organizations are installed provides a level of safety that is afraid to be lost. This situation blurs the vision of the agent of change, making creative thinking harder to achieve.
} 


\section{Organizational Development: Socio-Technical Theory and Planned Change Models}

The model of socio-technical change describes the relationships between elements in the face of change and innovation in any enterprise (Raineri 2001). Since a systemic approach is taken, there can be an integral vision of the business performance, made by the technical and social systems. The sociotechnical model says that change begins in the lower hierarchic level. Each sub-system is structured by (Raineri 2001):

- Technical or technological subsystem: Is composed by physical facilities, tasks, equipment, machinery, land, services, instruments, operation techniques, and physical environment. It sets limits on what can be done and creates needs for the internal organization.

- Social Subsystem: Composed by individuals with physical and psychological characteristics, internal social relationships and organizational demands, formal and informal. The social subsystem transforms the potential efficiency into real efficiency.

- Managerial subsystem: Organizational structure, policies, procedures, rules and the system of rewards and penalizations. It is the way decisionmaking and other elements useful for management processes are done. It is all the information that gives structure to the social and technical subsystems.

Figure 1 shows the interrelation between these subsystems in the planning process of the businesses.

Figure 1. Elements of the Socio-technical Model

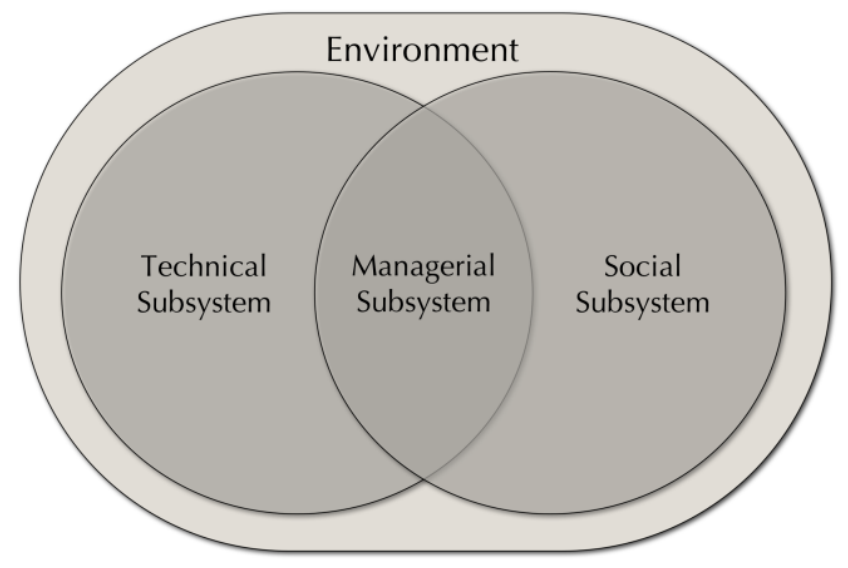

Source: Adapted from French et al. (2007).

Valderrama et al. (2014) points that MSB presents physical installations that are sometimes located in the house of one of the participants, as main characteristics of the technical system. With respect to the social system, we are talking about businesses where the members are family, with limited initiative for 
change, but with high solidarity and empathy. Finally, in the managerial subsystem, the organizational structure is often fuzzy, with permeable divisions and little accountancy and managerial structures to allow planning change and innovation.

On the other side, one of the first models of planned change that explained organizational changes is Lewin's, who parts from the definition of change as the modification of forces that hold a systems behavior stable (Jones 2013). Here, the process of change goes through three phases. First, an unfreezing of conduct patterns, mores, and the existing operation styles of the business. Secondly, experimentation and implementation of these new patterns, mores and operation styles, training included. Lastly, the new patterns and mores are expected to consolidate (Jones 2013).

To ignite the change spiral, the model considers a force analysis, based on the premise that the process of change is a result of the balance between thriving and opposing forces (Burnes 2004). For small businesses, with more structure than the micro ones, this analysis allows us to take the best and most objective course of action. Anticipating systematically the resistances that can present, the planning process is more efficient. A way to represent this analysis is shown in Figure 2.

Figure 2. Lewin's Model of Planned Change

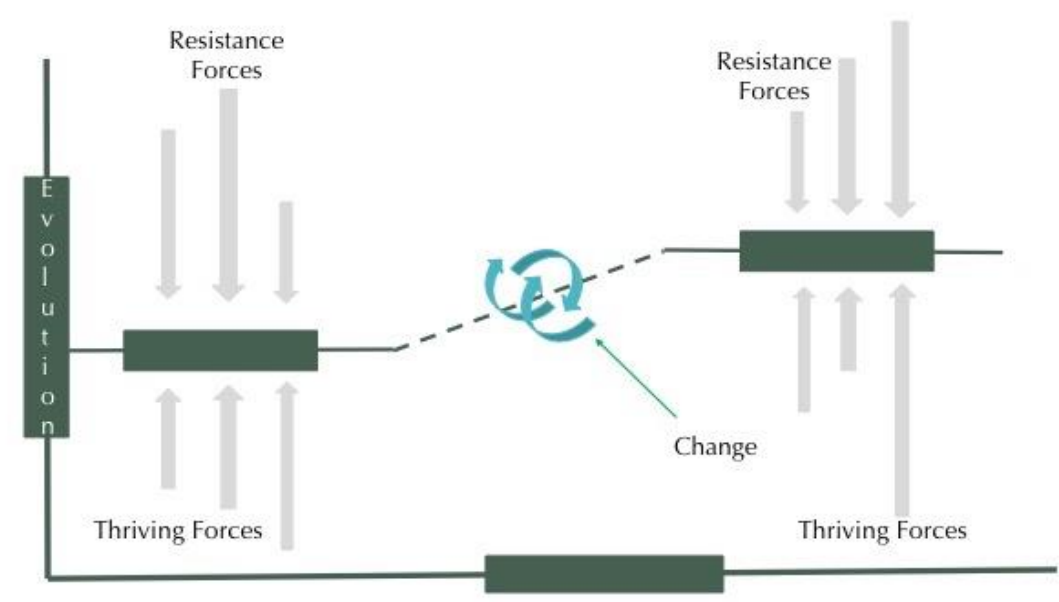

Source: Adapted from Jones (2013).

Yet another planned change model is the positive model. For Cummings and Worley (2009) this focuses on the firm's best practices. Therefore, the process identifies everything that gives good results, with the support of the implicated personnel. Through the technique of creation in dreams -imagination- the desired future is chosen; afterwards various ways to create that future are designed and proposed. This is summarized in Figure 3. 
Figure 3. Positive Model of Change

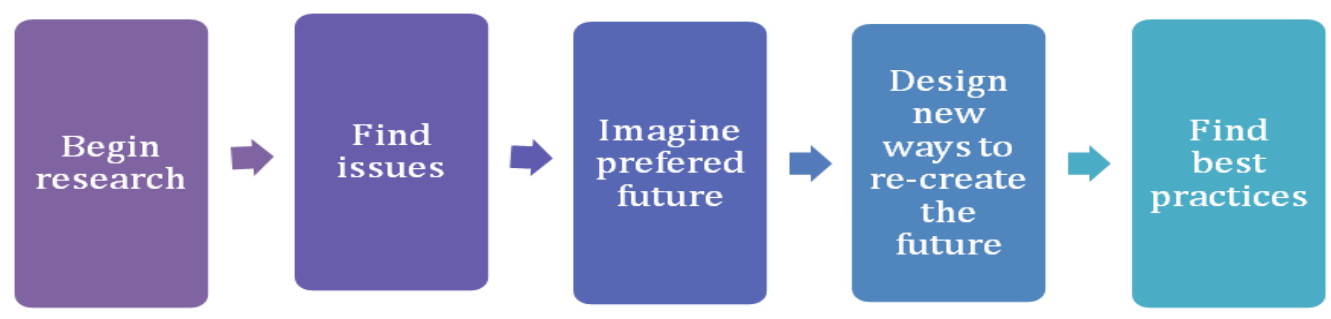

Source: Adapted from Cummings and Worley (2009).

These models of change are related with organization, planning, and continual improvement processes. They stress the importance of having an analysis of the starting point of the system, along with a goal or a desired future to achieve. It is important to identify the individuals that provide social skills such as leadership, teamwork, and conflict solution, among others, to promote sustainable processes of change.

\section{Human Skills for Innovation}

Firms have integrated to their everyday activities not just managerial, structural or leadership aspects, but they have also transformed the vision, placing the individual in the center of the stage, through a systemic and humanistic conception where the individual is proactive (Pereira 2007). According to the theory of human capital, education, experience and skills increase, accumulation of knowledge and vision for business. The human capital of entrepreneurs is positively associated with the creation of new businesses, employment growth, capacity to attract and retain clients and strategic allies. Thus, the essence of entrepreneurship is the individual and his or her skills.

\section{The Essence of Innovation}

To Varela (2013), activities of the firms are conditioned by their environment. According to the OECD (2005) innovation is the introduction of a product (good or service) or a process, either new or significantly improved, or the introduction of commercialization and organizational methods. In this process, sharing ideas throughout the firm contributes with motivation, compromise, learning and linkage for its application in new products and processes (Pérez 2007).

Innovation is thus generated by the individual and driven by organizations. For Van de Ven (1986), Amabile (1988) and King (1990) innovation is made by ideas and, since it is people who create, develop, and modify ideas, the source of innovation is the individual. Furthermore, to innovate in the firm, 
individuals with skills and characteristics similar to that of a leader (Drucker 1998) are needed; innovative idea-generating individuals are important, but also those capable of implementing those ideas in the workplace are of value (Hammond et al. 2011). Competences for innovation depend fundamentally on four factors: skills, motivation, attitudes and knowledge (Swoyambhu 2012). Figure 4 summarizes the nature of the innovation under this model.

Figure 4. Factors that Allow Innovation

Source: Swoyambhu (2012).

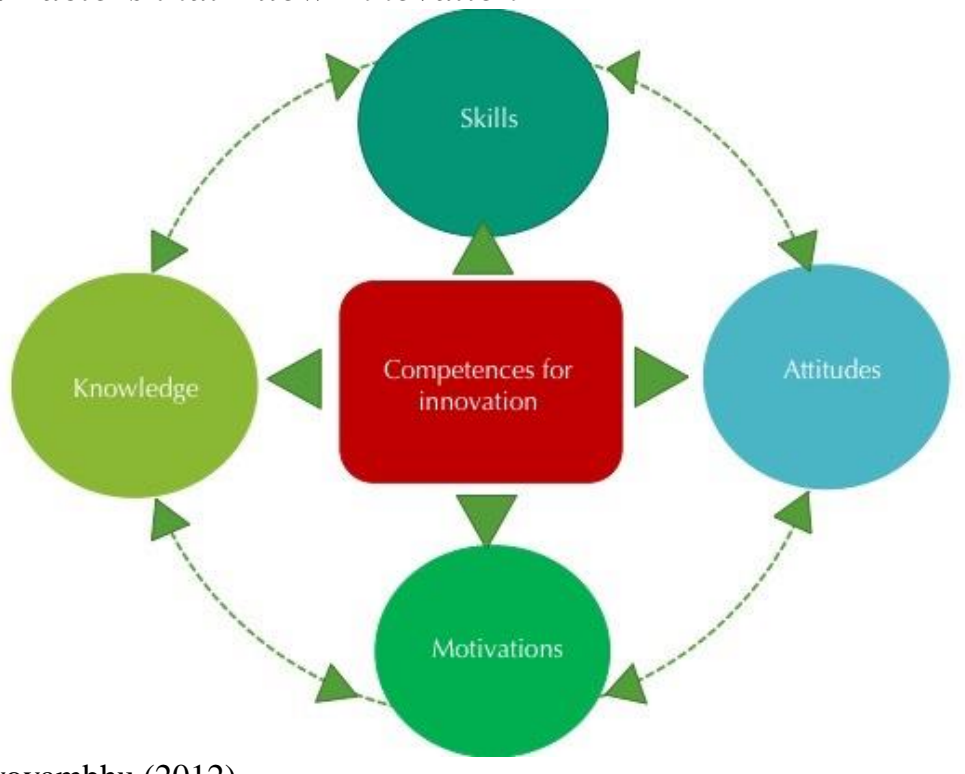

Skill is everything that has to do with cognitive capacities ${ }^{3}$ and, therefore, can be innate or can be learned. Motivation is something that stimulates a need to change. Attitude means the reaction in the face of different situations. Knowledge is the set of data that allows taking action.

Innovation can be considered part of the entrepreneurship process ${ }^{4}$. In this sense, to Muñoz (2010) creativity is a process previous to innovation. Whilst the creative process implies the generation of ideas, the innovative process is about the materialization of some of these ideas. Farr et al. (2003) describe the process of innovation in two fundamental stages: creativity and implementation.

The process of creation or invention refers to the efforts to generate new ideas, whilst innovation involves the materialization of them ${ }^{5}$. There are individuals that have notable abilities to create new ideas but lack the skills needed

\footnotetext{
${ }^{3}$ It means capabilities of thought, where it is usually taken that diverse skills imply the brain functioning that leads to cogitation, synthesis, analysis, judgment, etc.

${ }^{4}$ With respect of this, Drucker (2002) points that there is confusion about the definition of entrepreneurship. Although for some this term is related with small businesses, whilst for other it is about new businesses, he concludes that the term has nothing to do with the size or age of a business, but to a certain kind of activity.

${ }^{5}$ Freeman and Soete (1997) consider invention an outline or model of a mechanism, product, process or system, new and improved from creativity.
} 
to get them done ${ }^{6}$. The final process, known as entrepreneurship, is the exploiting of the materialized idea; it includes commercial development, application and transference. Figure 5 shows the nature of innovation in an entrepreneurial environment.

Figure 5. Proposed Innovation Spiral

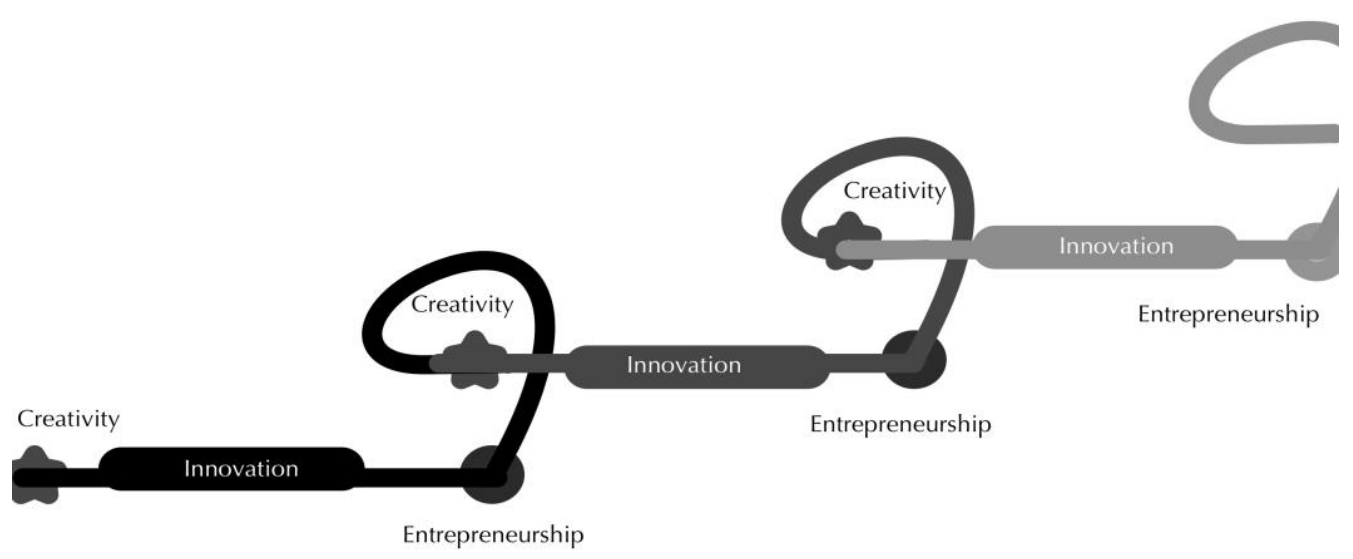

Source: Authors' constructions.

Thus, entrepreneurship starts in a creation process, followed by a process of innovation, where human skills allow taking information from the world of ideas to reality. This last part of the process is known as the entrepreneurship phase.

\section{Intellectual Capital as a Factor That Allows Innovation}

There are three kinds of capital used in the firm and required to make innovations and entrepreneurship: human, structural and relational. Combined, they construct intellectual capital (Sánchez et al. 2007). Structural capital is the set of knowledge that stays in the firm independently of the permanence of its collaborators (Sánchez et al. 2007). The non-human intangibles of the organization are included here, i.e. organizational culture, internal processes, information systems, databases, learning infrastructure, use of ICT, etc. (MERITUM 2002).

For Sánchez et al. (2007), human capital refers to the tacit knowledge that the collaborator takes with him when he leaves the firm. Some parts of this knowledge are exclusive of the individuals and others can be generic to the firm. It includes knowledge, competences, experiences and skills of the people in the organization. The human capital has the capacity to innovate, to create, know-how, previous experience, work team, negotiation, flexibility, motivation, satisfaction, loyalty, etc.

\footnotetext{
${ }^{6}$ To Muñoz (2010), creativity is a process and a capacity to liberate imaginative freedom to generate original and valuable ideas that can be further materialized and used in the solution of problems or the creation of new concepts, materials, products, processes, services and opportunities.
} 
Lastly, the relational capital includes the value generated by the relationships of the firm with clients, suppliers and any group of interest, internal or external (Sánchez et al. 2007). It is the knowledge found in the organization relationships (Bontis 1999). The relational capital is based on trust and every aspect of relationships given between people, associates, suppliers, etc. It is the capital that allows the firm to get benefits from human relations. The relevance of this capital goes even further if we consider that the MSB are not isolated entities or systems, but a part of a larger system and relates with the other parts of it.

Intellectual capital is, thus, training, formal education and work experience, developed on an individual and organizational level. It is all the resources of knowledge (tangible or intangible) that a firm has, to create value and to build a competitive advantage in the long run (Jurczak 2008). It is the relations with clients and partners; it includes the innovative efforts, the organizational structure, knowledge and skills of the collaborators (Edvinsson and Stenfelt 1999). This capital is decisive in the transformation of tacit knowledge into innovation.

Both tangible and intangible capitals are important for MSB. According to Valderrama et al. (2014), collaborators in the MSB accept that when there is a shortage of economic capital, the intangible capital is a way to increase the structural capital.

\section{Human Skills: Basic, Secondary and Innovative}

It is possible to make a classification of the skills needed for innovation in three main groups. (1) Basic human skills: intuitive, emotional and intellectual, (2) secondary skills, like socialization, and (3) innovation skills that involve all others skills combined and developed. These skills are presented in Figure 6.

Figure 6. Proposed Human and Innovative Skills

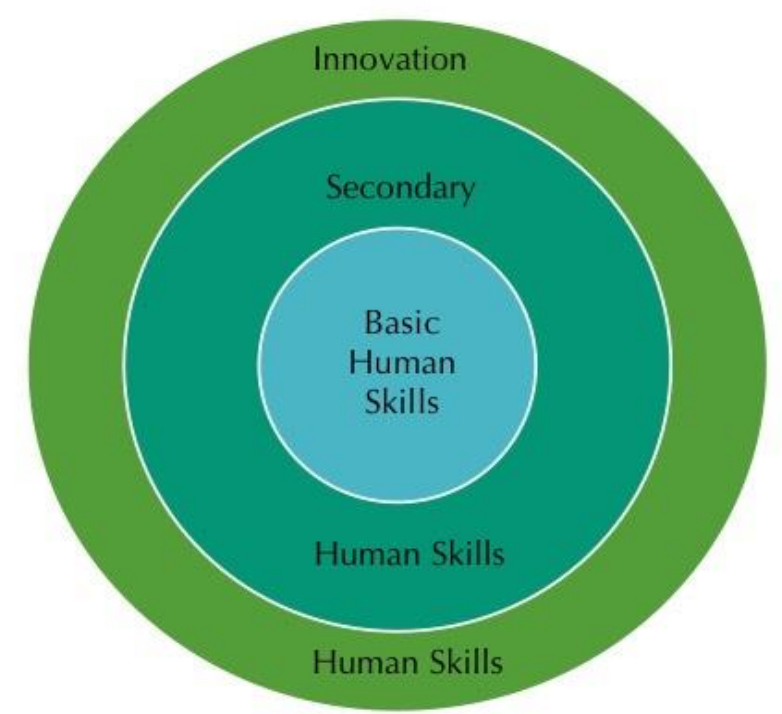

Source: Authors' constructions.

On a deeper level, the basic human skills are divided in: i) intuitive: observation, imitation, survival instinct, herd behaviors; ii) emotional: 
Differentiation, self-conception, empathy, tolerance of frustration, motivation and resilience; iii) intellectual skills: imagination, creativity, comparison, measurement, systematization, analysis/synthesis, reflection, etc. Basic intuitive skills are natural and innate, it is the basis of learning in children and everything is built from it. It is the ability to take decisions quickly based on previous experience. This does not mean that the decision is made randomly or just by a gut feeling.

Emotional intuitive skills allow the person and the firm to differentiate, through the recognition of basic limits and of self-conception. It refers to the identity of the organization, agreement with mission and vision of the business and recognizing what is offered to clients and suppliers, achieving empathy to increase relational capital. The firm requires tolerance to frustration, motivation and resilience.

Intellectual intuitive abilities imply imagination and creativity. It is associated with the capacity to compare, measure and systematize and it allows the business to classify and order information for the development of diverse functions, just as to evaluate the risk in the decision-making. The ability of analysis/synthesis and reflection leads the individuals and firms to learn from experiences identifying improvement.

Lastly, there are innovation skills that need basic skills as much as secondary ones. By the nature of innovation, we have a combination of skills that leads the individual or business from the creation or invention of new ideas to the materialization of them. Ideas transform into new, valuable products.

\section{Final Considerations}

Innovation is the main way for MSB to compete in the local markets. Contribution of people to innovation in these kinds of firms is substantial since their activities are intensive in the human capital. Thus, it is required that collaborators apply knowledge and skills to modify, change, or innovate, the goods and services they offer or the processes through which these products are generated. To innovate, we require that members of the organization propose new ideas, goods, concepts, services and practices to a certain aspect, activity or business. From this viewpoint, innovation is a continuous learning process, where tacit knowledge is found in the people and the firm's work teams.

Therefore, to maximize the benefits from innovation in the MSB, we need a staff that is able to generate new ways of thinking, feeling, organizing, creating and implementing. Furthermore, to walk through the innovation spiral, which implies going through a creativity stage to materialize these ideas in an entrepreneurship stage, requires the development of innovative characteristics in the individual.

Thus, reaching the benefits of innovation requires the MSB to face different behaviors, skills, knowledge and attitudes that befall on the individual. Therefore, they must manage several kinds of capital: human, structural and relational, all of them synthesized into the intellectual capital. 
In this process, the individuals can possess innate abilities to create ideas or implement them. Nonetheless, those that lack these abilities can count on developing them through three main kinds of interrelated skills. Basic human skills that are developed as the individual growth secondary skills that imply basic ones to relate with other people and build motivation, compromise and learning, and innovation skills, that involve every other skill combined and improved. Specifically, individuals with skills such as initiative, imagination, passion, empathy, activeness, focus, perseverance, compromise, and diligence are required. The importance of this group of abilities gets more notorious by following the systemic approach, where when one of these elements is modified it generates an effect on the others.

Lastly, innovation in the MSB depends on the capabilities of its workers to apply knowledge, experiences, abilities, attitudes and behaviors that allow them to generate, develop or modify products and processes and thus, differentiate from the competitors. Therefore, planned change that starts from individual and organizational learning represents an alternative to help MSB innovate, create value and get consolidated on different markets. Besides, the development of skills and knowledge of the individual that modifies the reality of MSB leads the firm to the creation of continuous learning dynamics that favors innovation.

\section{References}

Adecco (2013) IV Informe directivos y responsabilidad corporativa (VI directives and responsibility report). Fundación Adecco, España.

Amabile T (1988) From individual creativity to organizational innovation. In K Cronhaug, G Kaufman (eds.), Achivement and motivation: A social developmental perspective. New York: Cambridge University Press.

Bateson G (1990) Espíritu y naturaleza: Una unidad necesaria. Avances en teoría de sistemas, complejidad y ciencias humanas (Mind and nature: A necessary unit. Advances in system theory, complexity and human sciences). Barcelona: Amorrortú.

Bontis N (1999) Managing organizational knowledge by diagnosing intellectual capital: Framing and advancing the state of the field. International Journal of the Technology Management 18(5): 433-462.

Burnes B (2004) Kurt Lewin and the planned approach to change: A re-appraisal. Journal of Management Studies 41(6): 977-1002.

Cañeque H (2008) Alta Creatividad. Guía teórica-práctica para producir la innovación y el cambio (High creativity. Theory-practice guide to produce innovation and change). México: Prentice Hall.

Centro Ericksoniano de México (2014) Teoría de Sistemas (System Theory). México D.F.

Cummings T, Worley C (2009) Desarrollo organizacional y cambio (Organization development and change). México: Cengage Learning.

Drucker P (1998) Peter Drucker on the profession of management. Cambridge: Harvard Business Review Book.

Drucker P (2002) La gerencia en la sociedad futura (Management in future society). Bogotá: Grupo Editorial Norma. 
Edvinsson L, Stenfelt C (1999) Intellectual capital of nations for future wealth creation. Journal of Human Resource Costing and Accounting 4(1): 21-33.

Farr J, Sin H, Tesluk P (2003) Knowledge management processes and work group innovation. In V Shavinina (eds.), The international handbook on innovation. New York: Elsevier Science.

Freeman C, Soete L (1997) The economics of industrial innovation. London: Routledge.

French W, Well C, Zawacki R (2007) Desarrollo organizacional, transfomación y administración efectiva del cambio (Organization development, transformation and effective change management). Mexico: McGrawHill.

Gómez G (2006) Son iguales todas las empresas familiares? (Are all family businessess made equal?). Mexico: Norma.

Hammond M, Neff N, Farr J, Schwall A, Zhao X (2011) Predictors of individual level innovation at work: A meta-analysis. The Psychology of Aesthetics, Creativity, and the Arts 5(1): 90-105.

Jones G (2013) Teoría organizacional. Diseño y cambio en las organizaciones (Organization Theory. Design and change in organizations). Mexico: Pearson.

Jurczak J (2008) IC measurement methods. Economics and Organization of Future Enterprise 1(1): 37-45.

King N (1990) Innovation at work: The research literature. In M West, J Farr (eds.), Innovation and creativity at work: Psychological and organizational strategies. Chichester: Wiley Press.

Lizzati S (2008) El Cambio del Comportamiento en el Trabajo (Behavior Change at the Work). Buenos Aires: Granica.

MERITUM (2002) Guidelines for managing and reporting on intangibles (Intellectual Capital Report). Madrid: Vodafone Foundation.

Morales I (2011) Las PYMES en México, entre la creación fallida y la destrucción creadora (SMBs in Mexico, between failed creation and creative destruction). Economía Informa 366: 39-48.

Muñoz R (2010) Coaching creativo (Creative coaching). México: Panorama.

OECD (2011) Skills for innovation and research. Organization for Economic Cooperation and Development. Paris: OECD Publishing.

OECD (2005) Oslo Manual: Guidelines for Collecting and Interpreting Innovation Data, 3rd Edition. The Measurement of Scientific and Technological Activities. Paris: OECD Publishing.

Pereira F (2007) La evolución del espíritu empresarial como campo del conocimiento. Hacia una visión sistémica y humanista (The evolution of entrepreneural spirit as a field of knowledge. Towards a systemic and humanist view). Cuadernos de Administración 20(34): 11-37.

Pérez M (2007) Fundamentos en la dirección de la empresa familiar. Emprendedor, empresa y familia (Foundations in family bussiness management. Entrepreneur, firm and family). Madrid Paraninfo.

Raineri A (2001) Administración del cambio organizacional en empresas chilenas (Organizational change management in Chilean firms). Estudios de Administración 8(2): 1-41.

Robbins S (1999) Comportamiento organizacional (Organizational Behavior). México: Prentice Hall.

Sánchez A, González A, Pérez E (2007) El concepto de capital intelectual y sus dimensiones (The intellectual capital concept and its dimensions). Investigaciones Europeas de Dirección y Economía de la Empresa 13(2): 97-111. 
Senge P (2004) La quinta disciplina. El arte y la práctica de la organización abierta al aprendizaje (The fifth dicipline. The art and practice of an organization open to learning). Buenos Aires: Granica.

Swoyambhu M (2012) Innovation: Key factor to increasing competitiveness of small and medium enterprises. International Conference on Technology and Innovation Management, Nepal.

Valderrama A, Neme O, Oviedo L (2014) Diagnóstico de habilidades humanas y de innovación en las micro y pequeñas empresas: El individuo innovador (Diagnostics of human skills and of innovation in micro and small firms: The innovative individual). Mimeo.

Van de Ven A (1986) Central problems in the management of innovation. Management Science 32(5): 590-607.

Varela R (2013) Innovación empresarial. Arte y ciencia en la creación de empresas (Firm innovation. Art and science in the creation of firms). Bogota: Pearson.

Velásquez A (2007) La organización, el sistema y su dinámica: Una revisión desde Niklas Luhman (The organization, the system and its dynamics: a review from Niklas Luhman). Revista EAN 61: 129-156.

Ventura M, Salanova M, Llorens S, Zepeda F (2006) Factores Psicosociales para la Gestión de Calidad de las PyMEs: Un estudio de campo (Psychosocial factors for quality management of the SMBs). España: Jornades de Foment de la Investigació. 